\title{
Effects of teacher factors on expectations of students with ADHD
}

Lauren J. Legato

DePaul University, Llegato@depaul.edu

Follow this and additional works at: https://via.library.depaul.edu/etd

\section{Recommended Citation}

Legato, Lauren J., "Effects of teacher factors on expectations of students with ADHD" (2011). College of Liberal Arts \& Social Sciences Theses and Dissertations. 66.

https://via.library.depaul.edu/etd/66

This Thesis is brought to you for free and open access by the College of Liberal Arts and Social Sciences at Digital Commons@DePaul. It has been accepted for inclusion in College of Liberal Arts \& Social Sciences Theses and Dissertations by an authorized administrator of Digital Commons@DePaul. For more information, please contact digitalservices@depaul.edu. 


\title{
EFFECTS OF TEACHER FACTORS ON EXPECTATIONS OF STUDENTS WITH ADHD
}

\author{
A Thesis \\ Presented in \\ Partial Fulfillment of the \\ Requirements for the Degree of \\ Master of Arts \\ BY \\ LAUREN LEGATO \\ SEPTEMBER 14, 2010 \\ Department of Psychology \\ College of Liberal Arts and Sciences \\ DePaul University \\ Chicago, Illinois
}


THESIS COMMITTEE

Karen S. Budd, Ph.D.

Chairperson

Jocelyn S. Carter, Ph.D. 


\section{ACKNOWLEDGMENTS}

I would like to express my sincere gratitude to my thesis chair, Dr. Karen

Budd, and committee member, Dr. Jocelyn Carter, for their guidance and encouragement throughout this process. I would also like to thank the Chicago Public Schools for granting me permission to conduct my study with their teachers. I am grateful to the principals and teachers who took the time to complete the surveys for this study. Finally, I would like to acknowledge the Doctoral-Undergraduate Opportunities for Scholarship (DUOS) grant from DePaul University which provided the funding for conducting this research project, and the invaluable assistance from my DUOS undergraduate scholar, Adam Ramsey. 
The author was born in Washington, D.C., August 19, 1979. She received her Bachelor of Science degree from Vanderbilt University in 2001, and a Master of Arts degree in Clinical Psychology from Teachers College, Columbia University in 2007. 


\section{$\underline{\text { LIST OF TABLES }}$}

Table 1. Sample Size, Means, and Standard Deviations for Measures ........... 30

Table 2. Intercorrelations Among Measures ........................................ 30 


\section{$\underline{\text { LIST OF FIGURES }}$}

Figure 1. Visual Model of Hypothesized Relationships Among Variables ....... 18 


\section{TABLE OF CONTENTS}

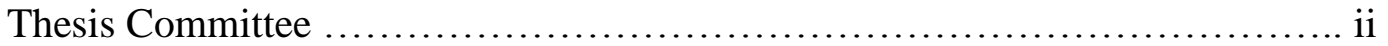

Acknowledgments................................................. iii

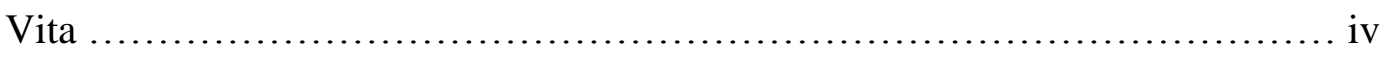

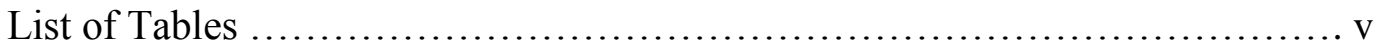

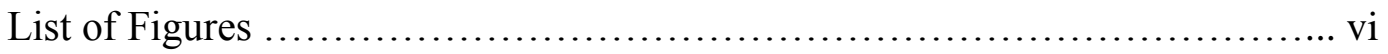

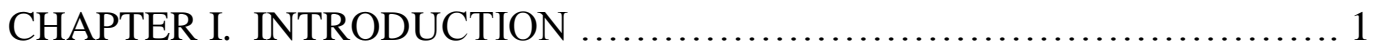

Teacher Knowledge $\ldots \ldots \ldots \ldots \ldots \ldots \ldots \ldots \ldots \ldots \ldots \ldots \ldots \ldots \ldots \ldots \ldots \ldots$

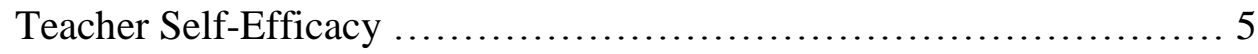

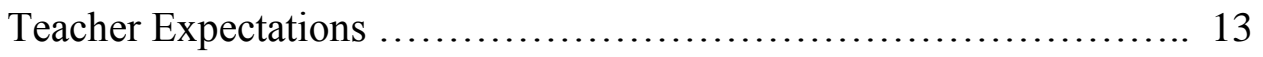

Rationale ..................................................... 16

Statement of Hypotheses and Research Questions .................. 18

CHAPTER II. METHODS ........................................... 20

Research Participants ........................................... 20

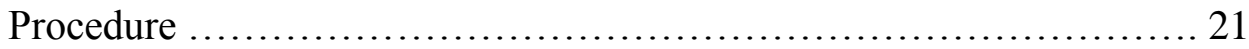

Measures ........................................................ 23

CHAPTER III. RESULTS ........................................... 29

CHAPTER IV. DISCUSSION ........................................... 39

CHAPTER V. SUMMARY ........................................ 45

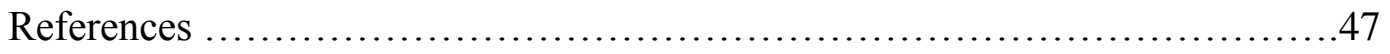

Appendix A. Teacher Information Form ............................. 54

Appendix B. Letter to Principals ..................................... 56

Appendix C. Chicago Public Schools Permission ......................... 58

Appendix D. Demographics Questionnaire ............................ 60

Appendix E. Teachers' Sense of Efficacy Scale ......................... 64 
Appendix F. Knowledge of Attention Deficit Disorders Scale . 66

Appendix G. Sample Vignettes 


\section{CHAPTER I}

\section{INTRODUCTION}

Attention-Deficit/ Hyperactivity Disorder (ADHD) is characterized by impairing symptoms of inattention and/or hyperactivity (American Psychiatric Association [APA], 2000). Prevalence rates in the general U.S. population fall between 3 and 8\% (APA, 2000), with estimates in school populations closer to 8\% (Gaub \& Carlson, 1997). Given the high incidence of ADHD in school populations, teachers are likely to teach multiple children with ADHD in their classrooms over the course of their careers. Disruptive behavior often associated with ADHD can be difficult for teachers to manage in the classroom and impairing for a child's academic, social, and emotional growth (Kos, Richdale, \& Hay, 2006).

Research has shown that untreated ADHD places children at risk for a host of problems that may persist and worsen in adulthood (Goksoyr \& Nottestad, 2008), including conduct problems (Wilens, Biederman, \& Spencer, 2002), academic underachievement (Barry, Lyman, \& Klinger, 2002), and substance abuse (Biederman, Wilens, Mick, Spencer, \& Faraone, 1999). Especially true in urban communities where mental health care access is limited (Atkins, Graczyk, Frazier, \& Abdul-Adil, 2003), teachers are often on the front line in seeking referrals for children and carrying out school-based interventions (Barbaresi \& Olsen, 1998; Graczyk et al., 2005). Without adequate knowledge or training on ADHD for addressing children's needs in the classroom, teachers may feel 
unprepared to handle the many challenges that children with ADHD can pose, and be less likely to seek services or support for their students. In two previous studies with elementary school teachers, $98-100 \%$ of teachers felt they could benefit from more training on ADHD and behavior management (Barbaresi \& Olsen, 1998; Kos, Richdale, \& Jackson, 2004).

Developing efficacious ADHD training models for teachers requires an understanding of how teachers perceive children with ADHD, and which teacher characteristics are most significant for addressing teachers' perceptions and training needs. Research that integrates teacher variables in relation to their expectations of children with ADHD is needed to fill in gaps in this literature. It is likely that teachers' perceptions of students with ADHD affect their behavior with students (Glass \& Wegar, 2000; Kos et al., 2006). Teacher factors such as tolerance of classroom behaviors, level of training, and treatment acceptability have been shown to affect learning and social outcomes for students with ADHD (Sherman, Rasmussen, \& Baydala, 2008).

The current study addressed these gaps in the literature by looking at the relationships among teachers' knowledge of ADHD, self-efficacy, and expectations about how behavior problems affect children and classrooms. Each of these three variables have been studied (e.g. Ohan, Cormier, Hepp, Visser, \& Strain, 2008; Sciutto, Terjesen, \& Bender Frank, 2000; Tschannen-Moran \& Hoy, 2007; Vereb \& DiPerna, 2004); however, this is the first study to explore the relationships among all three variables. 


\section{Teacher Knowledge}

Teachers' knowledge about ADHD has been studied descriptively, as well as in relation to treatment acceptability, teaching experience, and help-seeking behaviors. Previous studies have found mean percentages for correct answers on ADHD knowledge questionnaires to range from $48 \%$ to $76 \%$ (Jerome, Gordon, \& Hustler, 1994; Kos et al., 2004; Ohan et al., 2008; Sciutto et al., 2000). Variations in results may reflect methodological and measurement issues related to scale development and construct definitions (Kos et al., 2006). Although no direct relationship was found between ADHD treatment knowledge and treatment acceptability (Power, Hess, \& Bennett, 1995), experience teaching children with ADHD has been positively related to higher levels of knowledge (Jerome et al., 1994; Kos et al., 2004; Sciutto et al., 2000).

Ohan et al. (2008) grouped a sample of Australian teachers into high, average, and low categories of knowledge based on their responses to an ADHD knowledge survey. Teachers also responded to questions after reading vignettes about hypothetical students with ADHD. Teachers with high levels of knowledge were more likely to endorse seeking referrals for students and rating support services as beneficial for children with ADHD as compared to teachers with low knowledge. Teachers in the high and average knowledge categories were more likely to perceive that ADHD negatively impacted academic and social relationships than were teachers with low knowledge. On the other hand, teachers with low knowledge reported more confidence than the high or average groups in handling behavior problems without assistance. Ohan et al.’s (2008) study 
illustrated that teachers with higher levels of knowledge about ADHD may be more aware of the risk factors associated with the disorder, and therefore more likely to seek support services for students, which could lead to better outcomes for children with ADHD in their classrooms. However, the confidence expressed in the responses of teachers with low knowledge regarding the challenges that students with ADHD pose in the classroom may reflect naïveté to the students' needs and thus this pattern warrants further study.

Researchers have developed and employed a number of ADHD knowledge scales that vary according to the number of items, question formats, and construct definitions. The two most widely-used scales are those developed by Jerome (1994) and Sciutto et al. (2000). The current study uses Sciutto et al.'s (2000) Knowledge of Attention Deficit Disorders Scale (KADDS) for several reasons. First, unlike the Jerome (1994) scale, the KADDS includes a "Don't Know" answer choice in addition to the true-false format, which reduces the likelihood of chance guessing and distinguishes misconceptions from guesses. Second, the KADDS contains more items than the Jerome scale, which increases the reliability and sensitivity of the measure.

Further, the Jerome scale has generally been used with Australian samples, whereas the KADDS has demonstrated validity in a sample of urban, North American teachers similar to the target sample in the current study. Finally, the Jerome scale does not appear to adequately distinguish between teachers' factual knowledge of ADHD and their attitudes about the disorder (Kos et al., 2006). The 
KADDS appears to more clearly operationalize and capture the construct of teacher factual knowledge of ADHD.

Teacher Self-Efficacy

The construct of teacher self-efficacy is often used synonymously with teacher efficacy in the literature; however, some have argued that the two are theoretically distinct constructs (Dellinger, Bobbett, Olivier, \& Ellett, 2008; Tschannen-Moran, Hoy, \& Hoy, 1998). Teacher efficacy research began in 1976 with the Rand Corporation Change Agent study, for which researchers developed a brief 2-item measure of teacher efficacy grounded in Rotter's social learning theory (Rotter, Chance, \& Phares, 1972), focused mostly on his concept of locus of control (Tschannen-Moran \& Hoy, 2001; Tschannen-Moran et al., 1998). The Rand study sought to identify the extent to which student achievement was related to teachers' general and personal beliefs in their abilities to affect student motivation and learning (internal control) despite environmental obstacles (external control) such as lack of home support or school resources.

In the Rand study, teachers were asked to choose their level of agreement with each of two statements representing two supposedly distinct factors: general teaching efficacy (GTE) and personal teaching efficacy (PTE) (Tschannen-Moran \& Hoy, 2001; Tschannen-Moran et al., 1998). Together the two factors were thought to constitute the construct of teacher efficacy (TE). The first Rand item measured GTE and read: "When it comes right down to it, a teacher really can't do much because most of a student's motivation and performance depends on his 
or her home environment." The second item represented PTE and read, "If I really try hard, I can get through to even the most difficult or unmotivated students." The GTE item was considered to measure teachers' beliefs about the amount of internal control over student achievement that teachers had in general, and PTE was thought to capture beliefs about a teacher's own locus of control in the classroom which was based on extent of training and past experiences.

In the 1980s, several measures of teacher efficacy were developed that built upon the Rand work (Tschannen-Moran et al., 1998). As researchers attempted to build on the Rand conceptualization of teacher efficacy by creating more extensive measures, the construct became embroiled in confusion rather than moving towards a clearer conceptualization. The constructs of PTE and GTE based on the Rand tradition did not appear to cleanly correlate with distinct outcomes, causing researchers to later study the possibility of overlap between the two constructs (e.g. Guskey \& Passaro, 1994).

One study found GTE to explain variance in math achievement, whereas PTE contributed additionally to the variance in language achievement (Ashton \& Webb, 1986). Both are types of student achievement, and to date there has been no clear indication as to why GTE was related to math and PTE was related to language (Tschannen-Moran et al., 1998). High teacher efficacy (TE) assessed using the Rand family of measures has been correlated with better student achievement, lower teacher stress and burnout, and greater openness to implementing innovations. Correlates of PTE and GTE have been inconsistent across studies. 
Concurrently, a second line of research emerged based on Bandura's social cognitive theory (Bandura, 1977, 1986; Tschannen-Moran \& Hoy, 2001; Tschannen-Moran et al., 1998). Bandura's concept of teacher self-efficacy was concerned with teachers' future-oriented beliefs about their personal competence in a specific situation (Bandura, 1993; Tschannen-Moran et al., 1998). Teachers' personal efficacy beliefs about their teaching abilities were thought to affect the types of learning environments they created in their classrooms, which would subsequently influence student outcomes (Bandura, 1993). According to this theory, teachers with high self-efficacy would be more likely to perceive control over their ability to modify the environment and effect change.

Bandura's concept of perceived self-efficacy distinguished between selfperception of competence and actual competence (Tschannen-Moran et al., 1998). In addition, Bandura posited that teachers with high self-efficacy would not only possess skills to perform successfully, they would also be able to use their skills in the necessary conditions (Bandura, 1993). Actual competence would contribute to a teacher's sense of self-efficacy; however, teachers also had to possess a perception of competence in order to execute their skills under the necessary conditions as part of self-efficacy.

Social cognitive theory hypothesized two types of expectations related to efficacy. The first type of expectation, self-efficacy beliefs, has been widely agreed upon as synonymous with conceptualizations of PTE (Tschannen-Moran et al., 1998). However, controversy has ensued over the interpretation of the second expectation type, outcome expectancy. Bandura's theory distinguished 
between outcome expectancy and efficacy expectations. Bandura hypothesized that efficacy beliefs had to do with one's confidence in the ability to carry out a given task with sufficient competence. On the other hand, outcome expectancy referred to beliefs about the expected outcomes based on orchestrating the task at a given level of competence (Tschannen-Moran \& Hoy, 2001). The controversy over the interpretation of the distinction between outcome expectancy and efficacy in subsequent research will be discussed in greater detail next.

Researchers have used different measures of teacher self-efficacy based broadly on both Bandura and Rotter's models, further muddying the waters surrounding self-efficacy measurement. The most widely-used measure of teacher self-efficacy has been the Teacher Efficacy Scale (TES; Gibson \& Dembo, 1984), which the authors reported had been based on Bandura's social cognitive model. Gibson and Dembo argued that the two-factor structure of their 30-item measure reflected the two expectancies of Bandura's social cognitive theory: self-efficacy and outcome expectancy.

Gibson and Dembo (1984) named the first factor personal teaching efficacy (PTE) and the second factor general teaching efficacy (GTE), respectively. Although the authors of the Teacher Efficacy Scale used the same terms coined by the Rand study, GTE and PTE, to describe the factors measured in the TES, the authors claimed that the construct of teacher efficacy was rooted in Bandura's model. This type of semantic and conceptual confusion has contributed to the lack of clarity surrounding the theory and measurement of teacher self-efficacy. 
More recently, researchers have identified a variety of conceptual as well as statistical problems with the factor structure of the TES, including conceptual discrepancies between outcome expectancy and GTE, poor correlations between the Rand factors and the TES, and several measure items that loaded onto both factors (Deemer \& Minke, 1999; Soodak \& Podell, 1996; Tschannen-Moran \& Hoy, 2001). As a result, the need arose to develop a more conceptually and psychometrically sound measure of teacher self-efficacy.

Tschannen-Moran and colleagues (1998) developed a new theoretical model that integrated Bandura and Rotter's conceptualizations of teacher efficacy and self-efficacy, and proposed a new measure for studying it. In their model, teacher self-efficacy is conceptualized as the sum of two factors that are related to, but not synonymous with, GTE and PTE. The first dimension, similar to GTE, is analysis of the teaching task. As with GTE, analysis of the teaching task focuses on external factors of teachers' beliefs, such as students' abilities and motivation, appropriate types of instructional strategies, and quality of available resources, but it includes more specific aspects than the single question used in the initial Rand study. However, whereas the Rand group considered GTE a general measure of a teacher's perceived ability to manage external challenges, Tschannen-Moran and colleagues' factor of analysis of the teaching task includes teacher perceptions of external factors, such as students' abilities and motivation, appropriate types of instructional strategies, and quality of available resources.

Tschannen-Moran et al.'s (1998) second factor, related to PTE, is selfperceptions of teaching competence based on the present levels of functioning. 
Self-perception of teaching competence is measured using questions that assess perceptions of current functioning, which contribute to a teacher's prediction of future capabilities. These items assessing self-perceptions provide teachers the opportunity to report on personal strengths and challenges faced in the context of their teaching duties, such as competence in classroom management (TschannenMoran \& Hoy, 2001). Therefore, the definition of teacher self-efficacy used in the current study is taken from Tschannen-Moran's and colleagues' (1998) conceptualization that teachers "weigh their self-perceptions of personal teaching competence in light of the assumed requirements of the anticipated teaching task" (p. 231).

In Tschannen-Moran's model (1998), teacher self-efficacy exists within an intrapersonal and environmental context, and operated in a cyclical manner. Consistent with Bandura's ideas about sources of efficacy information, teachers take in and interpret information about teaching tasks based on past mastery experiences, levels of emotional and physiological arousal, training, and support factors. How a teacher interprets these sources of information influences teacher self-efficacy. Together, these cognitive processes and self-efficacy beliefs are hypothesized to result in a relatively stable set of efficacy beliefs over time, which would be predictive of future teacher behavior.

Tschannen-Moran and colleagues (1998) hypothesized that teachers consider their self-perceptions of competence in light of the expected requirements of the task. Given this hypothesis, it seems that knowledge in a given area would likely affect teachers' perceived requirements of a task. For 
example, a teacher with knowledge of the challenges a student with ADHD can pose to classroom management may have more realistic expectations about his or her competence in managing students' behavior when there is a student with ADHD in the classroom. Therefore, it is plausible that knowledge of ADHD may interact with teacher self-efficacy to predict teachers' expectations of student achievement as well as future teacher behavior.

Tschannen-Moran and colleagues' model formed the conceptual basis for the measure of self-efficacy used in the current study. Tschannen-Moran's measure, the Teachers' Sense of Efficacy Scale (TSES), was chosen for several reasons. First, it has shown improved reliability and validity over other measures of teachers' self-efficacy (Tschannen-Moran \& Hoy, 2001). The TSES has demonstrated evidence for being a more comprehensive assessment of previously developed constructs of teacher efficacy through positive correlations to PTE and GTE factors on the TSE and Rand measures. Further, the TSES has demonstrated a unified and strong factor structure in multiple factor analyses. Finally, Tschannen-Moran's measure has increased the predictive value and generalizability of PTE assessment by limiting the scope of efficacy beliefs to items most relevant to tasks involved in effective teaching practices.

Several findings related to teacher self-efficacy using a variety of selfefficacy measures have supported the cyclical nature of Tschannen-Moran's model. For instance, teacher self-efficacy has been shown to be inversely correlated with teacher burnout (Egyed \& Short, 2006; Friedman, 2003). Selfefficacy has also been found to mediate the relationship between stress and 
burnout in teachers, with low self-efficacy preceding burnout (Schwarzer \& Hallum, 2008). Further, structural equation modeling provided empirical support for a cyclical model of self-efficacy in which disruptive behaviors were shown to lower teacher self-efficacy of classroom management skills, leading to increased burnout levels over time (Brouwers \& Tomic, 2000). Given the increased risk that children with ADHD pose for teacher stress and burnout, it is necessary to better understand if and how both knowledge of ADHD and high teacher self-efficacy may serve as a protective factor against stress and burnout. To date, studies have not specifically examined this possibility. 


\section{$\underline{\text { Teacher Expectations }}$}

One way to assess the effect that knowledge and self-efficacy may have on teachers' behaviors is to measure teachers' expectations of students with ADHD. Teachers' expectations of students with ADHD have generally been studied under the umbrella of teachers' knowledge of and attitudes toward ADHD (Kos et al., 2006) without any clear differentiation or operationalization. Hepperlen, Clay, Henly, and Barke (2002) created a measure designed to assess teacher attitudes and expectations in the context of a test of ADHD knowledge. Questions related to teacher expectations of students with ADHD asked about future expectancies for children, such as percentage of ADHD children pursuing higher education and risk of substance addiction for ADHD adolescents, as well as current misconceptions, such as likelihood that a child with ADHD comes from a disorganized home or also suffers from bipolar disorder. Nonetheless, teacher expectations or perceptions were not clearly operationalized.

Another study attempting to investigate teacher perceptions of students with ADHD examined the perceptions of high school teachers(Rush \& Harrison, 2008). Teachers were provided with 76 index cards, each of which contained a perceptual statement about students with ADHD, and were told to sort the cards by putting statements together that seemed related. Hierarchical cluster analysis was used to create concept maps of related statements, resulting in a final solution of nine clusters. The results identified a number of thematic concerns related to teaching students with ADHD, such as classroom management and the need for expert support; however, the categories were too broad to be useful in creating an 
operationalized definition of teacher perceptions. Nonetheless, the data did appear to show that training is related to teachers' perceptions of students with ADHD, supporting the idea that knowledge of ADHD may be related to teachers' expectations.

Ohan et al. (2008) have produced the clearest operationalization of teacher expectations thus far in their study relating knowledge about ADHD to teachers' expectations for teaching a student with ADHD. Questions following vignettes asked for teachers' ratings for each hypothetical child presented regarding predictions for future behavior in terms of disruption to classroom, disruption to peers and social relationships, and teachers' confidence in managing the child's symptoms. Ohan and colleagues found level of ADHD knowledge to be significantly related to teachers' expectations of symptom interference in the classroom, with peers, and teacher confidence in handling the misbehavior. More specifically, teachers with high and average knowledge were more likely to acknowledge that ADHD would interfere in the classroom and that they would feel less confident in (i.e., would have lower expectations of) their ability to handle the behavior without assistance.

Furthermore, teachers have been found to relate teaching children with ADHD to increased stress (Greene, Beszterczey, Katzenstein, Park, \& Goring, 2002) and have tended to overidentify students with disruptive behaviors as having ADHD, especially as class size increased (Glass \& Wegar, 2000). Therefore, understanding factors related to teachers' expectations regarding children with ADHD become even more critical when considering overcrowded 
school environments with large class sizes. The current study sought to offer a clearer operationalization of teacher expectations as they relate to children with ADHD in the classroom environment. In the current study, teacher expectations were defined as opinions that teachers hold about how behaviors related to ADHD affect the child, the classroom environment, and the teachers themselves. 


\section{$\underline{\text { Rationale }}$}

Given the high prevalence of children with ADHD in schools, teachers are likely to teach multiple students with ADHD over the course of their careers, especially in urban settings. Without adequate knowledge or training, teachers may feel unprepared to handle the many challenges that children with ADHD can pose in the classroom, and may be less likely to seek services or support for their students. Urban teachers are at high risk for burnout given their often challenging work environment in under-resourced, overcrowded schools where children may be at higher risk for poor academic and mental health outcomes (Graczyk et al., 2005).

Studies have found that teachers often hold misconceptions of ADHD, which can lead to less accurate teacher expectations and fewer help-seeking behaviors for children with ADHD. Teachers with low knowledge of ADHD and inexperience in working with children with ADHD may be at increased risk for higher stress and burnout, especially in under-resourced and overcrowded urban schools. Teachers' knowledge about ADHD has been studied descriptively, as well as in relation to treatment acceptability, teaching experience, and helpseeking behaviors. The current study looked at teacher knowledge in relation to variables that have not yet been comprehensively studied together.

Although theoretical evidence exists that teachers' self-efficacy may interact with knowledge of ADHD, empirical studies are lacking in this area. Preliminary evidence has shown a positive correlation between teachers' self- 
confidence for implementing interventions and teacher knowledge of ADHD (Sciutto et al., 2000). However, this finding was based on only one question as part of a survey. Using Tschannen-Moran and colleagues' integrated model of teacher self-efficacy as a base, the current study expanded on this preliminary evidence by testing for self-efficacy as a moderator in the relationship between teacher knowledge of ADHD and their expectations for problems in the classroom for students with ADHD. To date, few studies have explored teacher variables in relation to teacher expectations for problems in working with children with ADHD.

In order to address the previously discussed gaps in the literature, the current study examined relationships among teachers' knowledge about ADHD, teacher self-efficacy, and teachers' expectations of how ADHD behaviors affect the child, the classroom environment, and the teacher's own well-being. Figure 1 provides a visual model of the hypothesized relationships among variables. Further, this study sought to explore the utility of an expanded measure of teacher expectations of students with ADHD in studying the relationship between teachers' knowledge of ADHD and self-efficacy. Teachers from urban schools serving low-income student populations were recruited as the target sample, given that increased stress and fewer resources place these teachers at higher risk for burnout. Results of this study are anticipated to contribute to the understanding of how teacher variables relate to expectations for children with ADHD in elementary school classrooms in urban schools. 
Figure 1. Visual Model of Hypothesized Relationships Among Variables

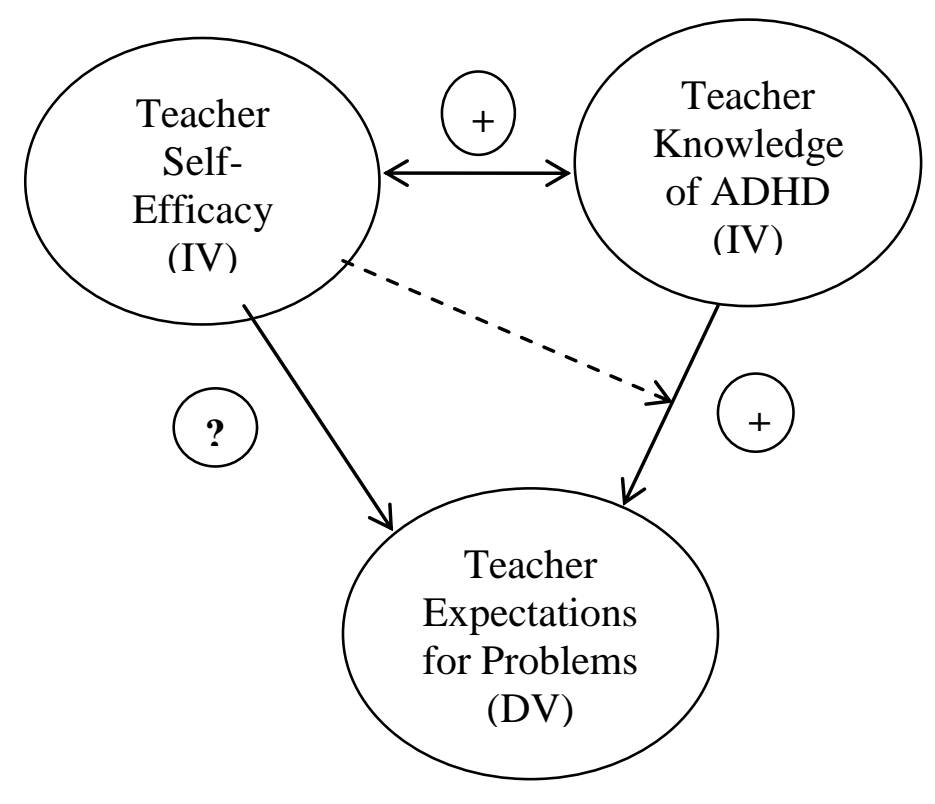

\section{$\underline{\text { Statement of Hypotheses and Research Questions }}$}

Hypothesis I. Higher ADHD knowledge will predict higher teacher expectations for problems.

Hypothesis II. Self-efficacy will moderate the relationship between knowledge of ADHD and expectations for problems. Specifically, teachers with higher knowledge and lower self-efficacy scores will have higher expectations for problems than teachers with high knowledge and high self-efficacy. Teachers with low knowledge will have fewer expectations for problems than teachers with high knowledge, regardless of self-efficacy level.

Hypothesis III. Teachers who have taught greater numbers of children with ADHD will have higher knowledge scores. 
Research Question I. How is self-efficacy related to teacher expectations for problems?

Research Question II. How are all three variables related to each other? 


\section{CHAPTER II}

\section{METHOD}

This section presents information on participant recruitment, study procedures, and measurement tools. Data were collected from elementary school teachers in the Chicago Public Schools (CPS).

\section{$\underline{\text { Research Participants }}$}

A total of 105 kindergarten through sixth grade elementary school teachers were recruited through a random sampling of study-eligible CPS schools. Schools serving students within the specified grade range qualified as recruitment sites if $80 \%$ or more of their student population was eligible for free or reduced lunch, and if they were located within 12 miles of the Lincoln Park neighborhood for travel feasibility purposes. Schools serving a majority of students who meet eligibility for free or reduced lunch are traditionally less well funded and well resourced than schools in areas serving families with higher incomes (Boyd \& Shouse, 1997). Therefore, it is likely teachers in study-eligible schools represented a more stressed population of teachers than those in suburban schools.

Teachers were recruited during data collections scheduled with school principals, and held before school and on in-service days. Depending on principal preference, teachers received notices of the data collection ahead of time in mailboxes, were notified by the principal via email or at a meeting, or responded to an announcement over the intercom system at the time of the data collection. Special education and student teachers were excluded from the study, but any 
classroom teacher of kindergarten through sixth grade was eligible to participate. Teachers received a $\$ 5$ gift card to their choice of coffee shop, restaurant, or fast food restaurant upon completion of the surveys, as well as an informational handout on managing students with ADHD in the classroom.

Teachers were $90 \%$ female. The majority of teachers identified as White (44\%), with an additional 36\% Latino/ Latina, 14\% African American/ Black, 5\% Asian/ Asian American, and 1\% Native American. Teachers generally had bachelors $(32 \%)$ or masters degrees $(66 \%)$, with $3 \%$ failing to report education level. The sample was relatively evenly divided among grade levels, kindergarten $(16 \%), 1^{\text {st }}$ grade $(16 \%), 2^{\text {nd }}$ grade $(13 \%), 3^{\text {rd }}$ grade $(16 \%), 4^{\text {th }}$ grade $(10 \%), 5^{\text {th }}$ grade $(11 \%), 6^{\text {th }}$ grade $(17 \%)$. The male teachers all taught $3^{\text {rd }}$ through $6^{\text {th }}$ grades. Teachers had a mean of 11.89 years $(S D=8.62)$ of experience as a teacher. The mean class size was $24.55(S D=5.84)$. Most teachers reported having taught at least one child diagnosed with ADHD over the course of their careers. As far as prior experience teaching students with ADHD, $16 \%$ of teachers reported having taught no children diagnosed with ADHD, 47\% reported having between one and five children diagnosed with ADHD over their careers, $14 \%$ reported having taught between six and ten children, and $20 \%$ had experience teaching eleven or more children diagnosed with ADHD.

\section{Procedure}

After obtaining university IRB approval and permission from the CPS Research and Review Board, schools were identified at random using a random 
numbers table of all schools meeting study inclusion criteria. Letters were mailed to six principals at a time with information about the study and inviting teachers at their school to participate (see Appendix C), followed by a phone call from the principal investigator up to two weeks later. After experiencing difficulty with reaching principals, principals at the largest schools on the study-eligible list were targeted with phone calls nearing the end of the study, and the study letter was emailed once principals expressed interest in the study over the phone. Five of the total eight schools were recruited using this method.

At the end of the study, 115 schools had been contacted over five months. Of the total number of schools contacted, 81 principals were unable to be reached, 21 schools refused or were excluded, and 13 schools agreed to participate in the study. Schools were counted as exclusions if they were primarily special education schools, had participated in a teacher training on ADHD by the DePaul clinic, or were closed. Of the 13 schools that agreed to be in the study, five schools either never followed through on scheduling data collections or did not have any teachers interested in participating. Therefore, the resulting 8 schools that participated in the study represented $7 \%$ of schools contacted. The return rate of surveys in each school ranged from 10-100\%.

Upon receiving principal consent, teachers at participating schools were invited to participate through their principal or vice principal either ahead of time or on the day of the data collection. If teachers did not complete the surveys at the time of the data collection, surveys were collected at a later date or returned in a pre-paid envelope. The surveys were available both in hard copy and online 
through Survey Monkey. Research has shown paper versus computer administration does not significantly affect survey responses or perceptions of confidentiality (Norman, Sallis, \& Gaskins, 2005; Uriell \& Dudley, 2009; Vereecken \& Maes, 2006; Wu \& Newfield, 2007).

\section{$\underline{\text { Measures }}$}

Survey packets contained one copy of each measure (demographics, selfefficacy, and ADHD knowledge) plus vignettes and expectation ratings in a stapled set or online format (see Appendices E-H). Participants first took the demographics questionnaire, then measures of knowledge, self-efficacy, and the vignette ratings, in that order. The directions for the vignettes stated that the children described displayed inattentive and hyperactive behaviors, which could have contaminated the ADHD knowledge scale if completed beforehand. The survey packet took an average of 35-40 minutes for teachers to complete.

\section{Demographic and Background Questions}

The first section of the survey packet contained background questions, including gender, age, ethnicity, highest degree attained, teaching experience (grade level currently teaching, number of years taught overall, number of years taught in current school, current class size), and experience teaching children with ADHD (number of students diagnosed with ADHD ever taught and number of students ever taught suspected, but undiagnosed, ADHD). Finally, teachers' training experience and interest with regard to ADHD was assessed (number of relevant courses in teacher preparation programs, estimated number of workshop 
hours attended, type of support from specially-trained school personnel, level of interest in receiving more training in teaching children with ADHD, and openended question about nature of interest in learning more about ADHD).

\section{Teacher Knowledge}

Teacher knowledge of ADHD was measured using the Knowledge of Attention Deficit Disorders Scale (KADDS; Sciutto et al., 2000). The KADDS is a 36-item rating scale designed to measure teachers' knowledge and misperceptions about ADHD as it relates to symptoms and diagnostic criteria, treatment, and general information about etiology and course of the disorder.

Participants read statements about $\mathrm{ADHD}$, and rate each statement as true (T), false (F) or don't know (DK). The DK options allows for differentiation between what teachers do not know and their misperceptions about ADHD. KADDS items refer to both positive and negative indicators of ADHD in order to account for a negative response bias. Sample items include: "Children with ADHD often fidget or squirm in their seats" (symptoms), "Behavioral treatment of ADHD focuses primarily on attention problems rather than non-compliance" (treatment), and "ADHD occurs in 15\% of school-aged children" (general information). Surveys were scored according to the number of questions answered correctly, with high scores indicating higher knowledge about ADHD. The KADDS demonstrated good internal consistency with a Cronbach's alpha of .86 in the current sample. 


\section{$\underline{\text { Teacher Self-Efficacy }}$}

Teachers' self-efficacy was measured using the long form of the Teacher's Sense of Efficacy Scale (TSES; Tschannen-Moran \& Hoy, 2001). The TSES is a 24-item measure designed to assess teachers' self-efficacy beliefs about a range of tasks related to teaching and learning within their school environment. All items were rated as "Important" or "Critical" tasks related to teaching by a sample of 224 inservice and preservice teachers (Tschannen-Moran \& Hoy, 2001). Factor analyses have revealed that a total score can be calculated, as well as three separate subscale scores: efficacy for instructional strategies, efficacy for classroom management, and efficacy for student engagement. Each question on the measure begins with some variation of "How much can you do to..." or "How well can you..." Sample questions from each subscale include: "How well can you respond to difficult questions from your students?" (Instruction), "How much can you do to control disruptive behavior in the classroom?" (Management), and "How much can you do to get through to the most difficult students?" (Engagement).

Teachers rated their confidence in their ability to address learning or behavior challenges on a Likert-type scale from 1 to 9 with anchors of 1 (nothing), 3 (very little), 5 (some influence), 7 (quite a bit), and 9 (a great deal). Ratings were summed to create a total mean score on the TSES with higher scores representing high levels of self-efficacy. The long form of the TSES demonstrated excellent reliability within the current sample, with internal consistencies of .96 for the total scale, .93 for Instruction, .92 for Management, and .90 for 
Engagement. The TSES has demonstrated construct validity through positive correlations with other measures of personal teaching efficacy, and discriminative validity for teacher self-efficacy using a measure of work alienation (TschannenMoran \& Hoy, 2001).

\section{$\underline{\text { Teacher Expectations }}$}

Teachers' expectations of students with ADHD were assessed using teachers' responses to questions based on a series of vignette descriptions of hypothetical children with ADHD symptoms. Vignettes and the accompanying questions were adapted for the current study by the principal investigator from materials used in a previous study obtained from one of the vignette's authors (personal communication, Jeneva Ohan, April 14, 2009). Internal consistencies across the six vignettes were good for the 10 questions, ranging from .81-.92 in the current study.

Each of the six brief vignettes described children with symptoms of both inattention and hyperactivity. Vignettes ranged ranged from 130 to 135 words long and described elementary school-aged children who clearly met Diagnostic and Statistical Manual of Mental Disorders, Fourth Edition (DSM-IV) symptom criteria for ADHD- Combined Type. Following is a sample vignette:

Nicola is 8 years old. Her teacher reports that Nicola spends more time roaming the room than in her seat. Her teacher also says that Nicola often doesn't appear to hear what is said, and turns in her work without having followed the assignment, finished it completely, or checked it over 
for errors. During playtime, she tries to climb the bookshelves when nobody is looking. In class she talks endlessly, even over others when they are in mid-sentence. Things are similar at home. Her parents can't get her to sit still long enough to do her chores or homework, as Nicola is always on-the-go or gets diverted by small things. Nicola has a tough time making friends, as they easily tire of her rambunctious behavior and her lack of patience with them.

In order to account for differences in teachers' expectations for behavior based on gender (Pisecco, Huzinec, \& Curtis, 2001; Sciutto, Nolfi, \& Bluhm, 2004), the presentation of vignettes were counterbalanced for gender of the child described in the vignette. In other words, half of the teachers read about three girls followed by three boys, and the other half of teachers read about the boys before the girls. Actual content of each vignette was presented in the same order to each participant; only names were changed in vignettes to specify gender (e.g. DanielDaniella, Eric-Erica, 2009).

An identical set of ten questions accompanied each vignette with only names changed to match the child in the vignette. Teachers provided a rating for each question on a Likert-type scale from 1 to 9, with anchors at 1 (Not at all), 5 (Moderate), and 9 (Extremely). The first seven questions assessed teachers' expectations of the severity of ADHD symptoms as they affected the child's life and schoolwork. The next two questions assessed the perceived impact of the student's behavior on the teacher, i.e. frustration and stress related to teaching the student. A tenth question assessed teachers' confidence in implementing an 
intervention with the child. Questions measuring the severity of ADHD on a child's life included: how serious are the behavior problems (1), how much impairment do the behavior problems cause in daily life (2), how disruptive are the behavior problems to those around (3), and how much would behavior problems interfere with: the child's family (4), the child's ability to make friends (5), the child's classroom (6), and academic progress (7). Impact on the teacher was assessed through questions about how stressful it would be to have the child as a student (8), and how frustrated the teacher would be with the behavior (9). The final question asked how confident the teacher would feel about implementing an effective intervention plan for the child (10).

Teachers' responses to the first nine questions on the expectation measure were summed for each vignette, and a total expectation score was computed for each participant by summing the scores from each vignette. The last question about teachers' confidence in implementing interventions was not included in the expectation score because it was determined to be too closely related to the construct of self-efficacy. Total expectation scores were considered to reflect teachers' overall expectations for problem levels for children with ADHD. 


\section{CHAPTER III}

\section{RESULTS}

This section describes descriptive data, the inferential statistics used to test each hypothesis, and the results of the analyses. SPSS 17 was used to conduct all analyses. Sample sizes for analyses and descriptive statistics, including means and standard deviations, are reported for each variable in Table 1. The mean knowledge score of $50 \%(M=17.82, S D=5.63)$ replicates previous findings from other studies using the KADDS in which elementary teachers answered about $50 \%$ of questions correctly (Scuitto et al., 2000; Sciutto, Nolfi \& Bluhm, 2004). Also consistent with previous research (Scuitto et al., 2000), teachers demonstrated better symptom and general knowledge than treatment knowledge on the KADDS. The mean self-efficacy score $(M=7.24, S D=1.02)$ suggests that teachers reported between "quite a bit" and "a great deal" of self-efficacy related to classroom duties. The mean for total self-efficacy scores in the current study is similar to elementary school teachers' mean of 7.1 in a previous study (Tschannen-Moran \& Hoy, 2001). Finally, teachers' mean score $(M=6.95, S D=$ 1.04) on the expectations measure shows teachers tended to rate children's ADHD symptoms as negatively affecting their functioning about halfway between moderately and extremely on the Likert-type scale provided. 
Table 1. Sample Size, Means, and Standard Deviations for Measures

\begin{tabular}{llll}
\hline Measure & $\boldsymbol{N}$ & $\boldsymbol{M}$ & $\boldsymbol{S D}$ \\
\hline KADDS $^{1}$ & 105 & 17.82 & 5.63 \\
TSES $^{2}$ & 102 & 7.24 & 1.02 \\
Expectations & 102 & 6.95 & 1.04
\end{tabular}

${ }^{1}$ Knowledge of Attention Deficit Disorders Scale (Sciutto, Terjesen, \& Bender Frank, 2000)

${ }^{2}$ Teacher Sense of Efficacy Scale (Tschannen-Moran \& Hoy, 2001)

Preliminary Analyses

As seen in Table 2, measures of knowledge (KADDS) and self-efficacy (TSES) had a small, but significant, positive correlation $(r=.25, p<.01)$.

Teachers' expectations were not significantly correlated to self-efficacy $(r=.12, p$ $=.23)$ or knowledge $(r=.07, p=.46)$. Teacher gender was significantly correlated with expectation $(r=-.38, p=.00)$ scores, such that being female was associated with lower ratings on expectation measures than for males. Teacher gender was not significantly related to self-efficacy or knowledge. Teachers' experience teaching children with ADHD was also significantly correlated with teacher gender $(r=.29, p=.00)$, meaning females tended to report having taught more students diagnosed with ADHD than males.

Table 2. Intercorrelations Among Measures

\begin{tabular}{lccccc}
\hline Variables & $\mathbf{1}$ & $\mathbf{2}$ & $\mathbf{3}$ & $\mathbf{4}$ & $\mathbf{5}$ \\
\hline 1. Gender & -- & & & & \\
2. Experience & $.29 * *$ & -- & & & \\
3. TSES & .00 & -.00 & -- & & \\
4. KADDS & -.10 & .14 & $.25^{*}$ & -- & \\
5. Expectations & $-.38^{* *}$ & -.18 & .12 & .07 & -- \\
$* p<.05, * * p<.01$ & & & & & \\
\hline
\end{tabular}


Differences between teachers who took the online surveys versus the paper surveys were examined for knowledge, self-efficacy, and expectations for problems variables. Scores were not significantly different for the two groups for knowledge or expectation ratings. However, teachers who took the online survey were significantly more likely than those who took the paper survey to give higher ratings of self-efficacy, $t(102)=2.88, p=.02$. Since the teachers who took the online survey were generally from one school, it was difficult to know whether this difference was attributable to the survey format or other differences inherent in the teachers from that particular school. In addition, male teachers had significantly higher expectation ratings than female teachers, $t(11.05)=2.93, p=$ .01 Therefore, teacher gender was considered as a covariate in all analyses involving expectation as DV.

A mean insertion method at the item level was used to replace random missing data points in order to calculate total scale scores for individuals. On the knowledge measure, missing data points were replaced with the item mode for the sample. In three cases, there was an even split among answer choices and the item mean was used. $20 \%$ of the sample had one missing data point out of a possible 36 items, which was replaced by an item mode or mean. In addition, one case was dropped due to too much missing data. On the self-efficacy measure, missing data points were replaced with the item mean for cases with three or fewer missing items out of the 24 possible items. $6 \%$ of the sample had missing items replaced by item means, and three cases were dropped as result of too much missing data. For the expectation measure, item means for each vignette were inserted for cases 
with missing items. Three cases were missing all items for one or more vignettes, and were subsequently dropped from the analyses. In summary, missing data replaced by means accounted for less than $1 \%$ of data collected on each measure once cases with large amounts of missing data were dropped.

Next the kurtosis for each variable was examined. For knowledge and expectation scores, there were no values greater than an absolute value of one or greater than two times the standard error, suggesting reasonably normal distributions for those variables (Tabachnick \& Fidell, 1996). However, for selfefficacy, the kurtosis statistic was larger than one and greater than two times the standard error of the kurtosis (.47) at 1.24. Therefore, it was concluded the distribution for self-efficacy had a significant kurtosis problem; specifically, the distribution was leptokurtic (i.e. too tall) given that the statistic was positive. This resulted from a large portion of the teachers (40\%) scoring between 7 and 8 on the self-efficacy measure.

Histograms and skewness statistics for each variable were also examined. These measures showed all variables to be moderately negatively skewed, which appeared to violate the assumption of normality. Thus square root transformations of these scales were computed to address the problems with skewness and kurtosis. The subsequent regression analyses were conducted using both the nontransformed and transformed scores, but the transformations were found not to make any significant differences to the overall amount of variance explained or the individual regression coefficients. Thus, for simplicity, only the nontransformed scores are reported. 


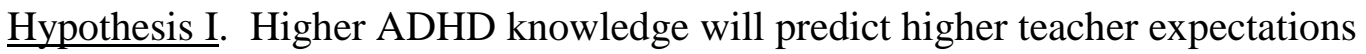
for problems.

In order to test the first hypothesis, teacher expectations for problems was regressed on ADHD knowledge in a linear regression model. Gender was initially included in the model as a predictor given its correlation with expectations, as previously mentioned. Gender was a significant predictor of expectations for problems and explained $14 \%$ of the total variance in expectations along with knowledge. However, gender was not a part of the hypothesis and including gender did not greatly affect the individual regression coefficients. Although greater overall variance in expectations was explained by including gender in the model, the hypothesis being tested was concerned with variance explained by knowledge alone. Therefore, results are presented without gender in the model.

Homoscedasticity was examined via several scatterplots and these indicated reasonable consistency of spread through the distributions. The assumption of normal distribution of residuals for regression was considered to be met. There were no outliers identified for knowledge using the test of leverage whereby leverage values exceeding three times the average value are considered extreme (Stevens, 1992). Six extreme outliers were identified on the expectations measure using Chatterjee and Hadi's (1988) criteria for Cook's distance, but none was considered influential using the criteria of values greater than one. Five outliers had expectations scores considerably lower than the mean $(M=375.45)$ for expectations, and one score was more than two standard deviations above the mean. However, all scores were within the possible score range and only the high 
score was extreme according to the possible range of scores. No cases were deleted from the subsequent analyses as they were determined to fit into a logical variance in scores.

Teacher knowledge of ADHD was the independent variable and expectations for problems served at the dependent variable. Total $N=105$ was reduced to 102 with the deletion of cases missing scores on the expectations measure. The model was nonsignificant for an effect of knowledge on teachers' expectation for problems, and produced a $R^{2}$ of $.05(F(1,101)=.54, p=.46)$. The hypothesis that teacher knowledge would predict higher teacher ratings of expectations for problems was unsupported as teacher knowledge was found to be a nonsignificant predictor in the model, $b=.80, t(102)=.73, p=.46$. Given the low model $R^{2}$, specification error was explored by including a quadratic term for knowledge to test for nonlinearity in the relationship. The overall model was nonsignificant, $R^{2}=.04, F(2,101)=1.78, p=.17$; however, the individual predictors both showed a trend toward significance when both knowledge, $b=$ $12.24, t(102)=1.83, p=.07$ and the quadratic term (knowledge by knowledge), $b$ $=-.38, t(102)=.73, p=.09$ were included in the model. The relationship of teachers' knowledge to their ratings of expectations for problems may not be linear in nature. As teachers' knowledge increases, at some point their expectations for problems appear to begin to decrease, although this does not occur for the current sample at a level that exceeds chance.

Hypothesis II. Self-efficacy will moderate the relationship between knowledge of ADHD and expectations for problems. Specifically, teachers with higher 
knowledge and lower self-efficacy scores will have higher expectations for problems than teachers with high knowledge and high self-efficacy. Teachers with low knowledge will have fewer expectations for problems than teachers with high knowledge, regardless of self-efficacy level.

In order to examine the second hypothesis, hierarchical regression analysis was performed to test for an interaction effect between knowledge (IV) and selfefficacy (IV) as they related to teacher expectations for problems (DV). A significant interaction term when controlling for main effects of self-efficacy and knowledge would indicate that self-efficacy moderates the relationship between knowledge and teacher expectations for problems. Total $N=105$ was reduced to 102 with the deletion of cases missing scores on the expectations measure. Predictor variables were centered before analyses were conducted. Teacher selfefficacy and knowledge were entered in Block 1, and an interaction term of knowledge by self-efficacy was entered into Block 2 .

The overall model regressing teacher expectations onto knowledge and self-efficacy (Block 1), and their interaction (Block 2), was not significant, $R^{2}=$ $.02, F(3,98)=.532, p=.66$. There was no main effect for knowledge, $b=.52, t$ $(102)=.46, p=.65$, or self-efficacy, $b=5.84, t(102)=1.03, p=.31$. In addition, the interaction term was nonsignificant, $b=-.08, t(102)=-.07, p=.94$; therefore, the second hypothesis stating self-efficacy would moderate the relationship between knowledge and expectations was not confirmed. 
Hypothesis III. Teachers having taught greater numbers of children with ADHD will have higher knowledge scores.

Univariate ANOVA was performed to examine the third hypothesis. Experience teaching children with ADHD was not significantly related to knowledge scores, $F(1,102)=1.95, p=.17$.

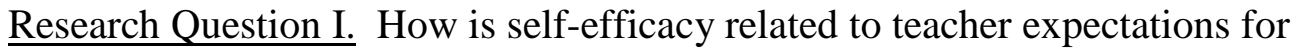
problems?

As explained under the second hypothesis, self-efficacy was unrelated to teachers' expectations for problems at a level beyond chance in a model including knowledge and a knowledge by self-efficacy interaction term. Following the same procedure used for the first hypothesis, gender was initially included as a predictor in a model regressing teacher expectations onto self-efficacy. Gender was a significant predictor of expectations for problems and explained $16 \%$ of the total variance in expectations in conjunction with self-efficacy. However, gender was not a part of the hypothesis and including gender once again did not greatly affect the individual regression coefficients. Although greater overall variance in expectations was explained by including gender in the model, the hypothesis being tested was concerned with variance explained by self-efficacy alone. Therefore, results are presented without gender in the model.

Homoscedasticity was examined via several scatterplots and these indicated reasonable consistency of spread through the distributions. The assumption of normal distribution of residuals for regression was considered to be 
met. There was one outlier identified for self-efficacy using the test of leverage whereby leverage values exceeding three times the average value are considered extreme. The self-efficacy score of 3.33 for this case was much lower than the mean $(M=7.25)$, but because it was still two standard deviations above the minimum score, the score was retained in the analyses. There were no extreme outliers identified on the expectations measure using the criteria of values greater than one as influential; however five extreme outliers were identified on the expectations measure using Chatterjee and Hadi's (1988) criteria for Cook's distance. Four outliers had expectations scores considerably lower than the mean $(M=375.45)$ for expectations, and one score was more than one standard deviations above the mean. However, all scores were within the possible score range, and none were considered terribly extreme according to the possible range of scores. No cases were deleted from the subsequent analyses as they were determined to fit into a logical variance in scores.

In a model by itself, the overall model regressing teacher expectations onto self-efficacy was nonsignificant, $R^{2}=.02, F(3,98)=.532, p=.66$. Teacher self-efficacy was found to be a nonsignificant predictor of teacher expectations, $b$ $=6.48, t(102)=1.19, p=.24$. Given the low model $R^{2}$, specification error was explored by including a quadratic term for self-efficacy to test for nonlinearity in the relationship. The overall model was nonsignificant, $R^{2}=.18, F(2,101) .70, p$ $=.48$. Self-efficacy does not appear to be related to teacher expectations in the current sample in a linear or curvilinear fashion.

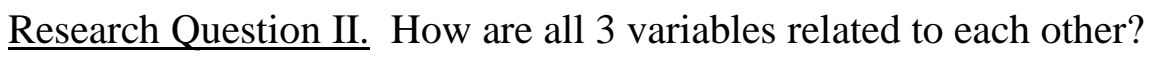


As mentioned in the results for the first two hypotheses, knowledge and self-efficacy were not predictive of expectation scores. Linear regression was also used to test the relationship between knowledge and self-efficacy. The overall model regressing knowledge onto self-efficacy was significant, $R^{2}=.25, F(1$, $102)=6.88, p=.01$. Self-efficacy significantly predicted knowledge scores, $b=$ $1.40, t(102)=2.62, p=.01$. Knowledge equally predicted self-efficacy when the direction was reversed and self-efficacy was regressed on knowledge, $b=.05$, $t(102)=2.62, p=.01$. Therefore, knowledge and self-efficacy appeared to be significantly related to each other, such that teachers with higher self-efficacy also tended to have higher knowledge of ADHD. 


\section{CHAPTER IV}

\section{DISCUSSION}

Teachers' knowledge about ADHD has been studied descriptively, as well as in relation to treatment acceptability (Power, et al., 1995; Vereb \& DiPerna, 2004), teaching experience (Jerome et al., 1994; Kos et al., 2004; Sciutto et al., 2000), and help-seeking behaviors (Ohan et al, 2008). The current study sought to fill a dearth in the literature on teacher variables related to expectations for students with ADHD by examining teacher knowledge in relation to self-efficacy in the classroom. Although theoretical evidence exists that teachers' self-efficacy may relate to knowledge of ADHD, empirical studies are lacking in this area. In one study, preliminary evidence has shown a positive correlation between teachers' self-confidence for implementing interventions and teacher knowledge of ADHD (Sciutto et al., 2000); yet another study found a negative correlation between confidence and knowledge (Ohan et al., 2008). These findings were both based on a single question about confidence on a survey. Therefore, the construct of teacher self-efficacy was included as an exploratory predictor.

The major goal of the current study was to examine relationships among teachers' knowledge about ADHD, teacher self-efficacy, and teachers' expectations of how ADHD behaviors affect the child, the classroom environment, and the teacher's own well-being. Self-efficacy was found to be significantly positively related to knowledge of ADHD, supporting the preliminary relationship evident in Scuitto et al.'s (2000) study. Teachers with 
higher knowledge also tended to have higher self-efficacy; however, it is unknown whether one is causally related to the other. One reason for this finding may be that teachers with more knowledge about ADHD are better able to recognize the challenges these students can pose, and therefore can maintain their feelings of competence in the classroom despite the children's challenging behavior. A competing argument is teachers with higher self-efficacy may be more likely to seek out knowledge to help them better support their students with ADHD than teachers with lower self-efficacy. Given the limited variability in the self-efficacy scores, a third explanation could be that teachers tended to present themselves in a positive light, thereby limiting the utility of the measure to capture a relationship between lower self-efficacy and knowledge.

The results of this study also provided replication of teachers' mean levels of knowledge about ADHD found in previous studies (Ohan et al., 2008; Vereb \& DiPerna, 2004; Sciutto et al., 2000). Teachers' knowledge of ADHD appears to be relatively consistent across samples, including in urban schools such as the current sample. Overall, knowledge and self-efficacy appear to be related to each other; however, future research with larger samples is necessary to further explore directionality of effects and interactions among other variables.

The first two hypotheses regarding the relationship of knowledge and selfefficacy to teacher expectations were unconfirmed. Results indicated neither teachers' knowledge of ADHD nor their self-efficacy in the classroom was related to their expectations for problems. Self-efficacy has historically proven to be a difficult construct for researchers to capture empirically. However, Tschannen 
and Moran's (1998) Teachers' Sense of Efficacy measure has shown predictive validity and good reliability in previous studies. It is difficult to ascertain whether a relationship does not exist between teacher expectations and knowledge, or whether too much measurement error existed in the expectations measure. Although the expectations measure showed good reliability in the current study, some of its items correlated as highly as .96, indicating possible multicollinearity effects. The measure had also not been well validated in its current form, and there may have been too much measurement error to detect effects of predictor variables. Furthermore, it is likely there was too little power to test for moderation effects given the small sample size of 102 teachers used in most analyses. A power analysis indicated a sample size of 107 was necessary to detect medium effect sizes using regression analysis; however, the current sample size was vastly insufficient to detect small effects as 776 teachers would have been needed.

Finally, the third hypothesis, that teachers who had taught greater numbers of students with ADHD would have higher knowledge scores, was unconfirmed. Unlike Sciutto et al. (2000), the currently study did not find experience in teaching students with ADHD and knowledge to be significantly related. Reasons for this inconsistency may be methodological, such as how the variable was measured, or due to a small effect size of the relationship making it difficult to detect. In addition, if teachers are not receiving a great deal of support for their students with ADHD, as may be the case in an under resourced, crowded urban school system, they may not be learning as much about ADHD from working with students as they do from trainings. In better resourced districts, teachers may 
gain "hands-on" experience with ADHD through collaborating with specialists, parents, and outside mental health professionals in supporting a child in school. Children from underserved areas may not be receiving collateral support, and therefore teachers would not have the opportunity to learn from their parents or other professionals about the child's needs.

A secondary goal of the study was to explore the utility of an expanded measure of teacher expectations of students with ADHD in studying the relationship between teachers' knowledge of ADHD and self-efficacy; however, this goal was not achieved with the particular measure used in the current study. Ohan and colleagues (2008) found teachers' knowledge of ADHD to be related to perceptions of treatment benefits, help-seeking behaviors for students, and severity ratings on vignettes of hypothetical children with ADHD. Perceptions of ADHD have also been found to be related to treatment acceptability (Graczyk, et al., 2005: Vereb \& DiPerna, 2004) and self-confidence (Graczyk, et al., 2005; Sciutto et al., 2000). In reviews of the literature on teacher factors, perceptions of ADHD have been cited as important variables in need of future research for better understanding how to improve interventions and trainings with teachers (Sherman et al., 2008; Kos et al., 2006; Glass \& Wegar, 2000). Operationalized definitions of teacher expectations still need to be constructed and tested for predictive utility. In addition, future research with larger samples is needed to provide additional power for detecting relationships among teacher variables and teachers' perceptions of ADHD. 
Several limitations exist in the current study. First, the small sample size restricted the ability to fully test relationships among variables. Second, all relationships detected among variables were associative in nature; causation and implications of the associations are unknown. For instance, it is unclear if higher teacher self-efficacy caused teachers to seek out more knowledge on ADHD, or whether higher knowledge protected teachers' self-efficacy. Further, there may have been a self-selection bias in that teachers who chose to participate may have more motivated, competent, or knowledgeable than teachers who declined to participate. Finally, within-school factors were not able to be controlled for in the current study. Because teachers who participated were only from eight schools, it is likely there are contamination effects from school factors. Schools were also mostly on the north side of the city so that results may not generalize to teachers in other areas of the school system.

Developing efficacious ADHD training models for teachers requires an understanding of how teachers perceive children with ADHD, and which teacher characteristics are most significant for addressing teachers' perceptions and training needs. Teachers appear to have ample room to learn more about ADHD and seem to want to do so, as $80 \%$ of the current sample reported being interested in more training regardless of length. The present study was aimed at contributing to better understanding how teacher variables relate to expectations for children with ADHD in urban, elementary school classrooms in order to inform future research and training models. 
The current findings were inconclusive about how cognitive factors, such as self-efficacy and teacher's knowledge of ADHD, are related to their behavior with children in the classroom. There are likely to be other, more salient constructs with greater implications for teacher training models on ADHD, such as environmental factors like levels of administrative support available to teachers. More specific expectation measures could be useful in future research, such as questions asking teachers about the likelihood of referral for services, or the likelihood about trying certain interventions with students. Future research should aim to improve the operationalization and empirical utility of teacher variables for further understanding the needs of teachers as they work to support students with ADHD in the classroom. 


\section{CHAPTER V}

\section{SUMMARY}

Symptoms of Attention Deficit/ Hyperactivity Disorder (ADHD) in children, such as inattention, hyperactivity, daydreaming, interrupting, fidgeting, and calling out, can be difficult for teachers to manage in the classroom, and impairing for a child's social and academic development. Studies have found that teachers often hold misconceptions of ADHD, which can lead to less accurate teacher expectations and fewer help-seeking behaviors for children with ADHD. Low teacher self-efficacy in the classroom has been shown to relate to stress and burnout. Teachers with low knowledge of ADHD and inexperience in working with children with ADHD may be at increased risk for higher stress and burnout, especially in under-resourced and overcrowded urban schools. Given the high incidence of ADHD in school populations, teachers are likely to teach multiple children with ADHD in their classrooms over the course of their careers.

The current study investigated the relationships between teachers' knowledge about ADHD, self-efficacy beliefs, and expectations regarding behavior problems of children with ADHD in a sample of urban elementary school teachers. Previous studies have examined knowledge of ADHD and teacher expectations; however, the current study undertook a more comprehensive exploration of how teacher factors related to expectations of students with ADHD by including the construct of self-efficacy. Identifying relationships among teacher variables salient in working with students with ADHD is important for 
improving professional development training and teacher interactions with students with ADHD.

One hundred and five kindergarten through sixth grade teachers from lowincome public schools in a large, Midwestern city completed surveys. Teachers were recruited during data collections scheduled with school principals, and held before school and on in-service days. Survey packets contained one copy of each measure (demographics, self-efficacy, and ADHD knowledge) plus vignettes and expectation ratings in a stapled set or online format. The survey packet took the teachers an average of 35-40 minutes to complete, and teachers received gift card compensation for their participation.

Regression analyses and ANOVA were conducted to examine hypotheses. Analyses indicated a significant relationship between knowledge and self-efficacy. Teachers with high knowledge were more likely to have higher selfefficacy scores. No relationship was detected between knowledge and expectations, or between self-efficacy and expectations. There was also no significant interaction effect between knowledge and self-efficacy for teacher expectations for problems. Finally, analyses revealed past experience teaching students with ADHD to be unrelated to teacher's level of knowledge about ADHD. Results demonstrated further research is needed to provide a more measurable operational definition for teacher expectations. Implications for future research and intervention planning are discussed. 


\section{REFERENCES}

American Psychiatric Association (2000). Diagnostic and statistical manual of mental disorders (4th ed., Text Rev.). Washington DC: Author.

Ashton, P. T., \& Webb, R. B. (1986). Making a difference: Teachers' sense of efficacy and student achievement. New York: Longman

Atkins, M. S., Graczyk, P. A., Frazier, S. L., \& Abdul-Adil, J. (2003). Toward a new model for promoting urban children's mental health: Accessible, effective, and sustainable school-based mental health services. School Psychology Review, 32, 503-515.

Bandura, A. (1977). Self-efficacy: Toward a unifying theory of behavioral change. Psychological review, 84, 191-215.

Bandura, A. (1986). Social foundations of thought and action: A social cognitive theory. Englewood Cliffs, N.J.: Prentice Hall.

Bandura, A. (1993). Perceived self-efficacy in cognitive development and functioning. Educational Psychologist, 28, 117-148.

Barbaresi, W. J., \& Olsen, R. D. (1998). An ADHD educational intervention for elementary school teachers: A pilot study. Journal of Developmental and Behavioral Pediatrics, 19, 94-100.

Barry, T. D., Lyman, R. D., \& Klinger, L. G. (2002). Academic underachievement and Attention-Deficit/Hyperactivity Disorder: The negative impact of symptom severity on school performance. Journal of School Psychology, 40, 259-283. 
Biederman, J., Wilens, T., Mick, E., Spencer, T., \& Faraone, S. V. (1999).

Pharmacotherapy of Attention-Deficit/Hyperactivity Disorder reduces risk for substance use disorder. American Academy of Pediatrics, 104, 20-24.

Boyd, W. L., \& Shouse, R. C. (1997). The problems and promise of urban schools. In O. Walberg, O. Reyes \& R. Weissberg (Eds.), Children and youth: Interdisciplinary perspectives (pp. 141-165). Thousand Oaks, CA: Sage.

Brouwers, A., \& Tomic, W. (2000). A longitudinal study of teacher burnout and perceived self-efficacy in classroom management. Teaching and Teacher Education, 16, 239-253.

Chatterjee, S. \& Hadi, A. S. (1988). Sensitivity analysis in linear regression. Hoboken, NJ: Wiley.

Deemer, S. A., \& Minke, K. M. (1999). An investigation of the factor structure of the Teacher Efficacy Scale. Journal of Educational Research, 93, 3-10.

Dellinger, A. B., Bobbett, J. J., Olivier, D. F., \& Ellett, C. D. (2008). Measuring teachers' self-efficacy beliefs: Development and use of the TEBS-Self. Teaching and Teacher Education, 24, 751-766.

Egyed, C. J., \& Short, R. J. (2006). Teacher self-efficacy, burnout, experience and decision to refer a disruptive student. School Psychology International, 27, 462-474.

Friedman, I. A. (2003). Self-efficacy and burnout in teaching: The importance of interpersonal-relations efficacy. Social Psychology of Education, 6, 191215. 
Gaub, M., \& Carlson, C. L. (1997). Behavioral characteristics of DSM-IV ADHD subtypes in a school-based population. Journal of Abnormal Child Psychology, 25, 103-111.

Gibson, S., \& Dembo, M. H. (1984). Teacher Efficacy: A Construct Validation. Journal of Educational Psychology, 76, 569-582.

Glass, C. S., \& Wegar, K. (2000). Teacher perceptions of the incidence and management of Attention Deficit Hyperactivity Disorder. Education, 121, 412-420.

Goksoyr, P. K., \& Nottestad, J. A. (2008). The burden of untreated ADHD among adults: The role of stimulant medication. Addictive Behaviors, 33, 342346.

Graczyk, P. A., Atkins, M. S., Jackson, M. M., Letendre, J. A., Kim-Cohen, J., Baumann, B. L., et al. (2005). Urban educators' perceptions of interventions for students with Attention Deficit Hyperactivity Disorder: A preliminary investigation. Behavioral Disorders, 30, 95-104.

Greene, R. W., Beszterczey, S. K., Katzenstein, T., Park, K., \& Goring, J. (2002). Are students with ADHD more stressful to teach?: Patterns of teacher stress in an elementary school sample. Journal of Emotional and Behavioral Disorders, 10, 79-89.

Guskey, T. R., \& Passaro, P. D. (1994). Teacher efficacy: A study of construct dimensions. American Educational Research Journal, 31, 627-643.

Jerome, L., Gordon, M., \& Hustler, P. (1994). A comparison of American and Canadian teachers' knowledge and attitudes towards Attention Deficit 
Hyperactivity Disorder (ADHD). Canadian Journal of Psychiatry, 39, 563-567.

Kos, J. M., Richdale, A. L., \& Hay, D. A. (2006). Children with Attention Deficit Hyperactivity Disorder and their teachers: A review of the literature. International Journal of Disability, Development and Education, 53, 147160.

Kos, J. M., Richdale, A. L., \& Jackson, M. S. (2004). Knowledge about Attention-Deficit/Hyperactivity Disorder: A comparison of in-service and preservice teachers. Psychology in the Schools, 41.

Norman, G. J., Sallis, J. F., \& Gaskins, R. (2005). Comparability and reliability of paper- and computer-based measures of psychosocial constructs for adolescent physical activity and sedentary behaviors. Research Quarterly for Exercise and Sport, 76, 315-323.

Ohan, J. L., Cormier, N., Hepp, S. L., Visser, T. A. W., \& Strain, M. C. (2008). Does knowledge about Attention Deficit Hyperactivity Disorder impact teachers' reported behaviors and perceptions? School Psychology Quarterly, 23, 436-449.

Pisecco, S., Huzinec, C., \& Curtis, D. (2001). The effect of child characteristics on teachers' acceptability of classroom-based behavioral strategies and psychostimulant medication for the treatment of ADHD. Journal of Clinical Child Psychology, 30, 413-421.

Power, T. J., Hess, L. E., \& Bennett, D. S. (1995). The acceptability of interventions for Attention-Deficit Hyperactivity Disorder among 
elementary and middle school teachers. Journal of Developmental and Behavioral Pediatrics, 16, 238-243.

Rotter, J. B., Chance, J. E., \& Phares, E. J. (1972). Applications of a social learning theory of personality. New York: Holt, Rinehart and Winston.

Rush, C., \& Harrison, P. (2008). Ascertaining teachers' perceptions of working with adolescents diagnosed with Attention-Deficit/Hyperactivity Disorder. Educational Psychology in Practice, 24, 207-223.

Schwarzer, R., \& Hallum, S. (2008). Perceived teacher self-efficacy as a predictor of job stress and burnout: Mediation analyses. Applied Psychology, 57, $152-171$.

Sciutto, M. J., Nolfi, C. J., \& Bluhm, C. (2004). Effects of child gender and symptom type on referrals for ADHD by elementary school teachers. Journal of Emotional and Behavioral Disorders, 12, 247.

Sciutto, M. J., Terjesen, M. D., \& Bender Frank, A. S. (2000). Teachers' knowledge and misperceptions of Attention-Deficit/Hyperactivity Disorder. Psychology in the Schools, 37, 115-122.

Sherman, J., Rasmussen, C., \& Baydala, L. (2008). The impact of teacher factors on achievement and behavioural outcomes of children with AttentionDeficit/ Hyperactivity Disorder (ADHD): A review of the literature. Educational Research, 50, 347-360.

Soodak, L. C., \& Podell, D. M. (1996). Teacher efficacy: Toward the understanding of a multi-faceted construct. Teaching and Teacher Education, 12, 401-411. 
Tabachnick, B. G., \& Fidell, L. S. (1996). Using multivariate statistics ( $^{\text {th }}$ ed.) Boston: Allyn \& Bacon.

Tschannen-Moran, M., \& Hoy, A. W. (2001). Teacher efficacy: capturing an elusive construct. Teaching and Teacher Education, 17, 783-805.

Tschannen-Moran, M., \& Hoy, A. W. (2007). The differential antecedents of selfefficacy beliefs of novice and experienced teachers. Teaching and Teacher Education, 23, 944-956.

Tschannen-Moran, M., Hoy, A. W., \& Hoy, W. K. (1998). Teacher efficacy: Its meaning and measure. Review of Educational Research, 68, 202-248.

Uriell, Z. A., \& Dudley, C. M. (2009). Sensitive topics: Are there modal differences? Computers in Human Behavior, 25, 76-87.

Vereb, R. L., \& DiPerna, J. C. (2004). Teachers' knowledge of ADHD, treatments for ADHD, and treatment acceptability: An initial investigation. School Psychology Review, 33, 421-428.

Vereecken, C. A., \& Maes, L. (2006). Comparison of a computer-administered and paper-and-pencil-administered questionnaire on health and lifestyle behaviors. Journal of Adolescent Health, 38, 426-432.

Wilens, T. E., Biederman, J., \& Spencer, T. J. (2002). AttentionDeficit/Hyperactivity Disorder across the lifespan. Annual Review of Medicine, 53, 113-131.

Wu, Y., \& Newfield, S. A. (2007). Comparing data collected by computerized and written surveys for adolescence health research. Journal of School Health, 77, 23-28. 
Appendix A

Teacher Information Form 


\section{Information Sheet for Participation in Research Study}

\section{EFFECTS OF TEACHER FACTORS ON EXPECTATIONS OF STUDENTS WITH ADHD}

You are being asked to participate in a research study being conducted by Lauren Legato, a graduate student at DePaul University, as a requirement to obtain her Masters degree. This research is being supervised by her faculty advisor, Karen Budd, Ph.D. We are asking you to participate because we are trying to learn more about teachers' experiences in the classroom with children who have problems of inattention and hyperactive behavior. This study will take about 35 minutes of your time. If you agree to be in this study, you will be asked to complete 3 surveys and answer some questions following brief descriptions of fictional children. The survey packet will include questions about your knowledge of Attention-Deficit/ Hyperactivity Disorder (ADHD), your feelings about various teaching tasks, and your opinions about the behavioral, academic, and social difficulties of 6 fictional children described in brief vignettes. As part of the survey, you will be asked to provide some personal, or demographic, information about yourself such as gender, age, ethnicity, grade taught, teaching employment history, and experience working with children with ADHD. Your answers to these questions are completely confidential and anonymous, and will in no way be linked back to you.

You can choose not to participate. There will be no negative consequences if you decide not to participate or change your mind later. You may choose whether you would like to complete a paper or online version of the survey packet. You will be compensated with a $\$ 5$ gift card to a store of your choice upon completion of your survey. If you choose to complete the survey online, you will be asked to provide your first name, grade level taught, and email address for compensation purposes only. Your answers will remain anonymous since your name and email address will not be connected in any way to your survey answers. Your name and email address will be destroyed after the study is over. No permanent record of your participation will remain after the study is over. If you choose to complete the paper survey, research personnel will return to your school the following week to collect your survey and provide you with a gift card.

If you have questions about this study, please contact Lauren Legato at 773-3257730 or llegato@ depaul.edu, or Karen Budd at 773-325-2020 or kbudd@depaul.edu. If you have questions about your rights as a research subject, you may contact Susan Loess-Perez, DePaul University's Director of Research Protections at 312-362-7593 or by email at sloesspe@ depaul.edu.

You may keep this information for your records. 
Appendix B

Letter to Principals 
Dear Principal:

The purpose of this letter is to invite teachers at your school to participate in a unique study being conducted by Lauren Legato, MA, a doctoral student in the Psychology Department at DePaul University, under the supervision of Dr. Karen S. Budd, professor and Director of Clinical Training in DePaul University's Psychology Department. The purpose of this research study is to better understand factors that affect teachers' perceptions of students with Attention Deficit/ Hyperactivity Disorder (ADHD). Teachers would be participating anonymously and no data would be linked to your school.

The long-term objective of the proposed research is to better understand factors affecting teachers' expectations of students with ADHD in order to inform the development of teacher training models. Your school was selected because $80 \%$ or more of your students qualify for free or reduced lunch. Teachers in urban schools serving low-income populations often face greater challenges in promoting children's academic and social growth, especially when working to support children with ADHD.

The current study will examine teacher factors, such as knowledge about ADHD and beliefs in how to handle challenges in the classroom, as they relate to expectations about how ADHD can impact a child's development, behavior in the classroom, and teacher stress and frustration. Specifically, the study will test the hypothesis that teachers with higher knowledge of ADHD are more likely to anticipate effects of ADHD symptoms on the child, the classroom, and their own well-being.

We would like to recruit teachers of grades kindergarten through six to complete a short packet of surveys. With your permission, teachers would be recruited through a brief announcement at the end of a faculty meeting or by speaking with teachers individually after school hours.

- Teachers would have the option to complete the surveys in the form of a paper packet or online.

- $\quad$ The survey packet should take approximately $\mathbf{3 5}$ minutes to complete. Surveys would always be completed outside of school hours, either at school or home.

- $\quad$ Teacher participants would be compensated with a $\mathbf{\$ 5}$ gift card to a store or restaurant of their choice (i.e., Target, Dunkin' Donuts, McDonald's, or Starbucks). In addition, we would be happy to provide your school with information sheets for teachers and parents about ADHD.

- $\quad$ Teachers would complete the surveys during the late Fall or early Winter, pending approval of the Chicago Public Schools Research and Review Board.

We are excited to collaborate with your school and look forward to hearing from you regarding any questions or concerns. Please contact graduate student Lauren Legato at 773-325-7780 or faculty advisor Karen Budd at 773-325-2020 should you have any questions or concerns. Thank you for your consideration of this request.

Sincerely,

Lauren Legato, MA and Karen S. Budd, PhD 
Appendix C

Chicago Public Schools Permission 
October 15, 2009

Dear Ms. Legato:

Thank you for your interest in conducting research in The Chicago Public Schools. The Research

Review Board of the Office of Research, Evaluation, and Accountability has reviewed your proposal for research entitled Effects of Teacher Factors on Expectations of Students with ADHD and has approved your request to conduct research. Although your study has been approved, school principals have final authority over activities that are allowed to take place in the school. If data collection continues beyond a year from this approval, please complete the Modification \& Continuing Review Process Checklist.

Upon completion of the research study, a copy of the final report or summary of the results must be provided to the Research Review Board. The Board reserves the right to use the information in the research report or summary for planning, solicitation of grants and staff development.

Please note that your study has been assigned Project ID \#409. If you have any questions, please contact Michelle Acker on my staff at 773-553-2452.

Sincerely,

Amy Nowell

Chair, Research Review Board

Office of Performance Management 
Appendix D

Demographics Questionnaire 


\section{DEMOGRAPHIC QUESTIONNAIRE}

1) Gender:

Female Male

2) Age: years

3) Ethnic/ Cultural Group (check all that apply):

Asian/ Asian American

Latino/ Latina

White (non-Hispanic)/ Caucasian
African American/ Black

Native American

Other (please specify:

4) Which grade level do you currently teach?

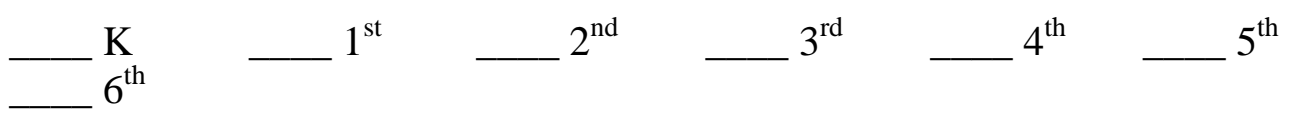

5) How long have you taught in your current school? years months

6) How long have you been employed as a teacher (in any school)? years months

7) What is your highest level of education?

$\mathrm{BA} / \mathrm{BS}$

MA/ MS

EdD/

$\mathrm{PhD} /$ other

doctoral level degree

BA/ BS + some graduate coursework

MA/ MS + further graduate coursework 
DEMOGRAPHIC QUESTIONNAIRE p. 2

8) What is your current class size? (If you teach more than one class, choose the class period with the largest class size.)

students

9) If you teach more than one class, how many total students do you currently teach?

students

OR I only teach one class

10) Including all of your years employed as a teacher up until today, how many of your students have/ had been given a diagnosis of ADHD that you know about?

none

$1-5$

$6-10$

$11-15$

more than 15

11) Including all of your years employed as a teacher up until today, how many of your students do you suspect might have had/have ADHD but were not diagnosed to your knowledge?

$$
\text { none }
$$

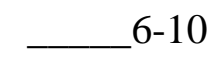

$11-15$ more than 15

12) How many college or graduate courses have you taken that covered ADHD-related material (if any)?

none

$1-3$

4-6

7-10

more than 10

13) How many workshops or trainings have you attended since becoming employed as a teacher that covered ADHD-related material (if any)?

none

$1-3$

4-6

$7-10$ more than 10 
DEMOGRAPHIC QUESTIONNAIRE p. 3

14) What kind of support does your school offer teachers for helping students diagnosed with ADHD? (Please mark all that apply.)

Special education services outside the classroom

Special education services in the classroom

Teaching assistant/ paraprofessional

Consultation with guidance counselor

Consultation with school psychologist

Consultation with special education teacher(s)

Other (please specify:

15) How interested would you be in receiving more training for teaching children with ADHD?

I would definitely be interested in any kind of training.

I would be interested as long as the training was brief.

I already feel that I know enough about ADHD.

I would not be interested in learning about ADHD.

16) What would you be most interested in learning more about in relation to ADHD? 
Appendix E

Teachers' Sense of Efficacy Scale- Long Form (TSES) 


\section{Teacher Beliefs}

Directions: This questionnaire is designed to help us gain a better understanding of the kinds of things that create difficulties for teachers in their school activities. Please indicate your opinion about each of the statements below. Your answers are confidential.

\section{How much can you do?}

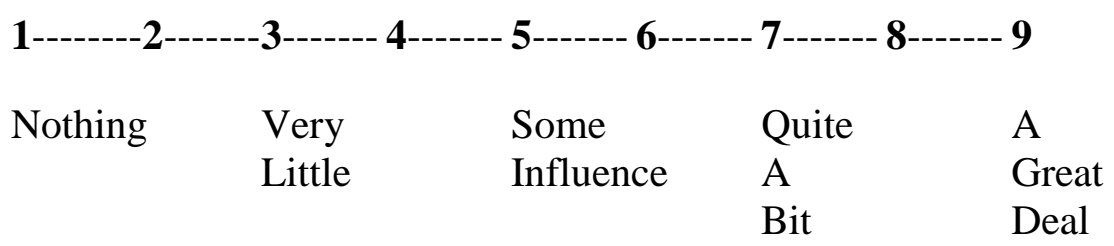

1. How much can you do to get through to the most difficult students?

2. How much can you do to help your students think critically?

3. How much can you do to control disruptive behavior in the classroom?

4. How much can you do to motivate students who show low interest in school work?

5. To what extent can you make your expectations clear about student behavior?

6. How much can you do to get students to believe they can do well in school work?

7. How well can you respond to difficult questions from your students?

8. How well can you establish routines to keep activities running smoothly?

9. How much can you do to help your students value learning?

10. How much can you gauge student comprehension of what you have taught?

11. To what extent can you craft good questions for your students?

12. How much can you do to foster student creativity?

13. How much can you do to get children to follow classroom rules?

14. How much can you do to improve the understanding of a student who is failing?

15. How much can you do to calm a student who is disruptive or noisy?

16. How well can you establish a classroom management system with each group of students?

17. How much can you do to adjust your lessons to the proper level for individual students?

18. How much can you use a variety of assessment strategies?

19. How well can you keep a few problem students form ruining an entire lesson?

20. To what extent can you provide an alternative explanation or example when students are confused?

21. How well can you respond to defiant students?

22. How much can you assist families in helping their children do well in school?

23 . How well can you implement alternative strategies in your classroom?

24. How well can you provide appropriate challenges for very capable students? 
Appendix F

Knowledge of Attention Deficit Disorders Scale (KADDS) 


\section{KADDS}

Please answer the following questions regarding Attention-Deficit/Hyperactivity Disorders (ADHD). If you are unsure of an answer, respond Don't Know (DK), DO NOT GUESS.

True (T), False (F), or Don't Know (DK) (circle one):

1.T F DK Most estimates suggest that ADHD occurs in approximately $15 \%$ of school age children.

2. T F DK Current research suggests that ADHD is largely the result of ineffective parenting skills.

3. T F DK ADHD children are frequently distracted by extraneous stimuli.

4. T F DK ADHD children are typically more compliant with their fathers than with their mothers.

5. T F DK In order to be diagnosed with ADHD, the child's symptoms must have been present before age 7 .

6. $\mathrm{T}$ F DK ADHD is more common in the 1st degree biological relatives (i.e. mother, father) of children with ADHD than in the general population.

7. $\mathrm{T}$ F DK One symptom of ADHD children is that they have been physically cruel to other people.

8. T F DK Antidepressant drugs have been effective in reducing symptoms for many ADHD children.

9. $\mathrm{T}$ F DK ADHD children often fidget or squirm in their seats.

10. $T$ F DK Parent and teacher training in managing an ADHD child are generally effective when combined with medication treatment.

11. T F DK It is common for ADHD children to have an inflated sense of selfesteem or grandiosity.

12. $\mathrm{T}$ F DK When treatment of an ADHD child is terminated, it is rare for the child's symptoms to return.

13. T F DK It is possible for an adult to be diagnosed with ADHD.

14. T F DK ADHD children often have a history of stealing or destroying other people's things. 
15. T F DK Side effects of stimulant drugs used for treatment of ADHD may include mild insomnia and appetite reduction.

16. T F DK Current wisdom about ADHD suggests two clusters of symptoms: One of inattention and another consisting of hyperactivity/impulsivity.

17. T F DK Symptoms of depression are found more frequently in ADHD children than in non-ADHD children.

18. T F DK Individual psychotherapy is usually sufficient for the treatment of most ADHD children.

19. T F DK Most ADHD children "outgrow" their symptoms by the onset of puberty and subsequently function normally in adulthood.

20. T F DK In severe cases of ADHD, medication is often used before other behavior modification techniques are attempted.

21. T F DK In order to be diagnosed as ADHD, a child must exhibit relevant symptoms in two or more settings (e.g., home, school).

22. $\mathrm{T}$ F DK If an ADHD child is able to demonstrate sustained attention to video games or TV for over an hour, that child is also able to sustain attention for at least an hour of class or homework.

23. T F DK Reducing dietary intake of sugar or food additives is generally effective in reducing the symptoms of ADHD.

24. T F DK A diagnosis of ADHD by itself makes a child eligible for placement in special education.

25. T F DK Stimulant drugs are the most common type of drug used to treat children with ADHD.

26. T F DK ADHD children often have difficulties organizing tasks and activities.

27. $\mathrm{T}$ F DK ADHD children generally experience more problems in novel situations than in familiar situations.

28. T F DK There are specific physical features which can be identified by medical doctors (e.g. pediatrician) in making a definitive diagnosis of ADHD.

29. T F DK In school age children, the prevalence of ADHD in males and females is equivalent. 
30. T F DK In very young children (less than 4 years old), the problem behaviors of ADHD children (e.g. hyperactivity, inattention) are distinctly different from age-appropriate behaviors of non-ADHD children.

31. T F DK Children with ADHD are more distinguishable from normal children in a classroom setting than in a free play situation.

32. T F DK The majority of ADHD children evidence some degree of poor school performance in the elementary school years.

33. T F DK Symptoms of ADHD are often seen in non-ADHD children who come from inadequate and chaotic home environments.

34. $T$ F DK Behavioral/Psychological interventions for children with ADHD focus primarily on the child's problems with inattention.

35. T F DK Electroconvulsive Therapy (i.e. shock treatment) has been found to be an effective treatment for severe cases of ADHD.

36. T F DK Treatments for ADHD which focus primarily on punishment have been found to be the most effective in reducing the symptoms of ADHD.

37. $\mathrm{T} F$ DK Research has shown that prolonged use of stimulant medications leads to increased addiction (i.e., drug, alcohol) in adulthood.

38. T F DK If a child responds to stimulant medications (e.g., Ritalin), then they probably have ADHD.

39. T F DK Children with ADHD generally display an inflexible adherence to specific routines or rituals. 
Appendix G

Sample Vignettes 


\section{SAMPLE VIGNETTES}

\section{Instructions}

On the following pages, there are descriptions of children who have inattentive, hyperactive, and/or defiant behaviors. When you read each description, please imagine that you are that child's teacher. After each description, there are questions for you to complete based on your experience and opinions as a teacher. If you are unsure how to respond, please go with your first impression or reaction. 
Daniel is a 9-year old boy. Daniel's teacher describes him as always moving, from squirming in his seat to wandering around the classroom, chattering endlessly instead of doing his work. His teacher says that Daniel doesn't do what she asks him to do, such as cleaning out his desk, despite her constant instructions. He starts work late because he often misplaces what he needs. While doing his work, he gets side-tracked into doing something else and turns in his work without checking. According to his parents, Daniel never seems to focus on what they say or ask of him, even when they repeat themselves. His behavior with others his age is similar. He often intrudes on what they are doing, and doesn't wait for his turn or concentrate on what's happening in their games.

1. How serious are Daniel's behavior problems?

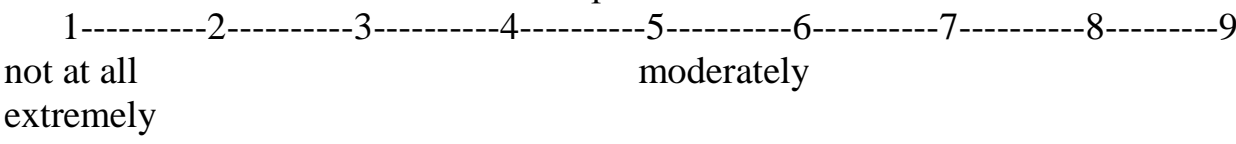

2. How much impairment do Daniel's behavior problems cause in his daily life?

none
extreme

3. How disruptive are Daniel's behavior problems to those around him?

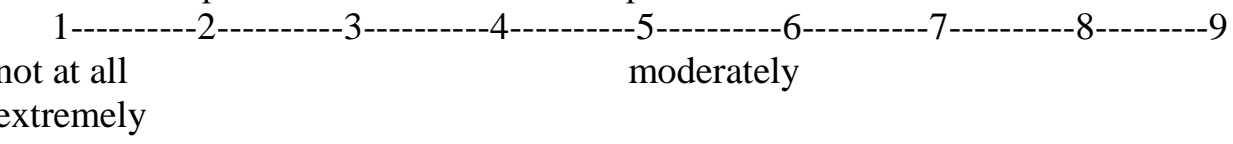

4. How much would Daniel's behavior problems interfere with the following: a) his family?

not at all moderate extreme

b) his ability to make friends and get along socially with other children?

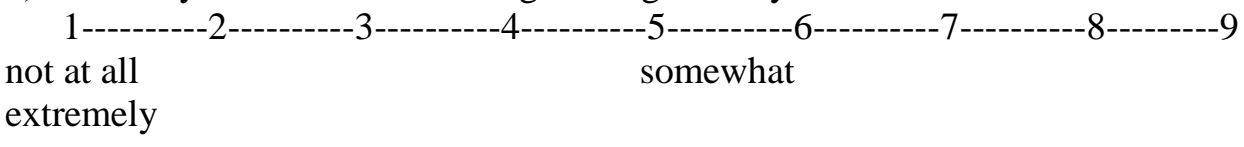

c) his academic progress?

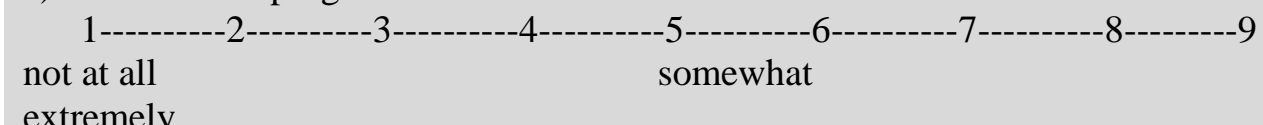

extremely

d) his classroom?

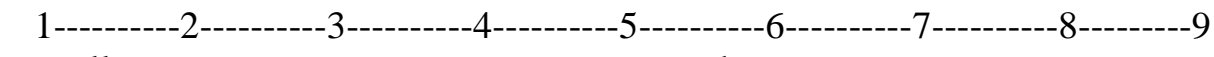

not at all somewhat

extremely

5. How frustrated would you be with Daniel's behavior during class?

1----------2----------3----------4----------5----------6----------7----------8---------9

not at all moderately

extremely 
6. How stressful would it be to have Daniel as a student?

1----------2----------3----------4----------5----------6----------7----------8---------9

not at all

moderately

extremely

7. How confident are you that you could implement an effective behavior plan for Daniel?

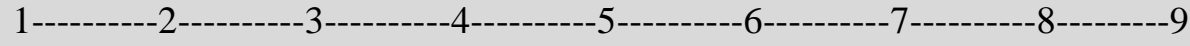

not at all moderate

extreme 
Daniella is a 9-year old girl. Daniella's teacher describes her as always moving, from squirming in her seat to wandering around the classroom, chattering endlessly instead of doing her work. Her teacher says that Daniella doesn't do what she is asked to do, such as cleaning out her desk, despite repeated instructions. Daniella starts work late because she often misplaces what she needs. While doing her work, she gets side-tracked into doing something else and turns in her work without checking. According to her parents, Daniella never seems to focus on what they say or ask of her, even when they repeat themselves. Her behavior with others her age is similar. She often intrudes on what they are doing, and doesn't wait for her turn or concentrate on what's happening in their games.

1. How serious are Daniella's behavior problems?

not at all
extremely

\section{How much impairment do Daniella's behavior problems cause in her daily life?

1----------2----------3----------4----------5---------6----------7----------8--------9 \\ none moderate \\ extreme}

3. How disruptive are Daniella's behavior problems to those around her?

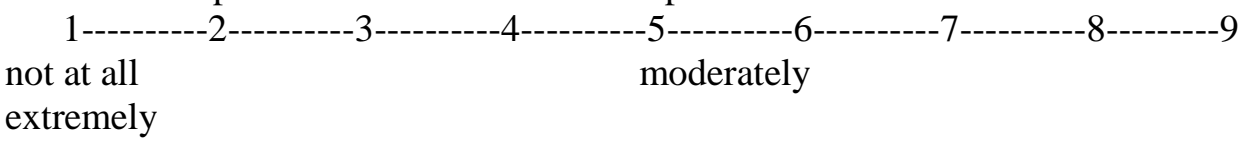

\section{How much would Daniella's behavior problems interfere with the following: a) her family?

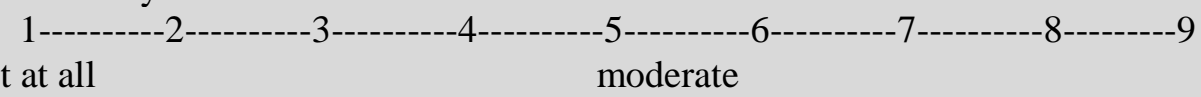 \\ not at all moderate \\ extreme}

b) her ability to make friends and get along socially with other children?

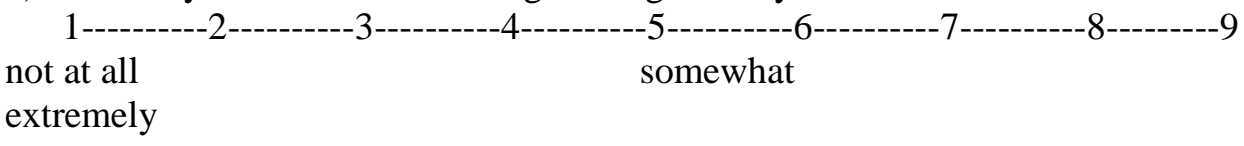
c) her academic progress?

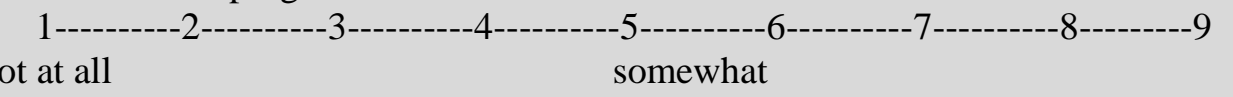

extremely

d) her classroom?

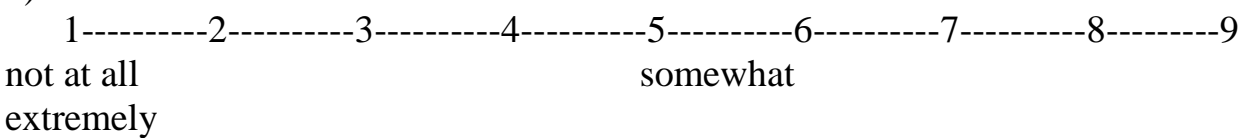
5. How frustrated would you be with Daniella's behavior during class?

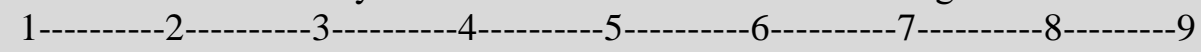 not at all moderately


extremely

6. How stressful would it be to have Daniella as a student?

1----------2----------3----------4----------5---------6----------7----------8---------9

not at all

moderately

extremely

7. How confident are you that you could implement an effective behavior plan for Daniella?

1----------2-----------3----------4-----------5----------6----------7----------8---------9

not at all

moderate

extreme 